\title{
An Update on Molecular Genetic Aberrations in Spitz Melanocytic Proliferations: Correlation with Morphological Features and Biological Behavior
}

\author{
Daja Šekoranja, Jože Pižem, Boštjan Luzar \\ Institute of Pathology, Faculty of Medicine, University of Ljubljana, Korytkova 2, 1000 Ljubljana, Slovenia \\ Correspondence: bostjan.luzar@mf.uni-lj.si; Tel.: + 3861543 7130; Fax.: + 38615437101
}

Received: 14 February 2021; Accepted: 15 March 2021

\begin{abstract}
The aim of the paper is to give an update on molecular genetic aberrations in Spitz melanocytic proliferations with special emphasis on their correlation with morphological features and biological behavior. The Spitz group of melanocytic proliferations is defined by a combination of distinctive morphological features and driver molecular genetic events. Morphologically, these neoplasms are characterized by large, oval, polygonal, or spindled melanocytes with abundant eosinophilic cytoplasm, vesicular nuclei with prominent nucleoli, often in association with epidermal hyperplasia. Molecular aberrations in Spitz melanocytic proliferations can be divided into two main groups, according to the driver genetic change: 1) 11p amplification/HRAS mutation, present in about $20 \%$ of cases, and 2) kinase fusions, present in about $50 \%$, further subdivided into tyrosine kinase fusions (ALK, ROS1, NTRK1, NTRK3, MET, RET) or serine-threonine kinase fusions (MAP3K8, BRAF). Driver genetic aberrations can be detected along the whole biological spectrum of Spitz melanocytic proliferations, and are mutually exclusive. Although driver genetic aberrations enable proliferation of melanocytes, additional genetic events (often biallelic inactivation of CDKN2A and TERT promoter mutations) are necessary for the development of overt Spitz malignancy. Conclusions. Recent studies have demonstrated that certain driver genetic aberrations are more often associated with the benign spectrum of Spitz melanocytic proliferations and indolent biological behavior (11p amplification/HRAS mutation, tyrosine kinase fusions). In contrast, some driver aberrations are more frequent in the atypical/malignant spectrum of Spitz melanocytic proliferations with a potential for aggressive biological behavior (serine-threonine kinase fusions). In addition, certain driver aberrations are often associated with distinctive morphological features. However, none of the morphological features is entirely specific for any of these driver genetic aberrations. Immunohistochemistry for ALK, ROS1, and pan-TRK can be used for screening purposes to detect corresponding fusion proteins.
\end{abstract}

Key Words: Spitz Melanocytic Proliferations - Kinase Fusions - 11p Amplification/HRAS Mutation • Morphology • Clinical Behavior.

\section{Introduction}

According to the most recent $4^{\text {th }}$ WHO Classification of Skin Tumours, the Spitz group of melanocytic proliferations is defined by a combination of morphological characteristics and driver molecular genetic abnormalities (1). Spitz melanocytic proliferations are characterized morphologically by a proliferation of large, oval, polygonal epithelioid or spindled melanocytes with abundant eosinophilic cytoplasm, vesicular nuclei with prominent nucleoli, often in association with epidermal hyperplasia (1). They encompass the whole biological spectrum of melanocytic proliferations, including Spitz nevi, atypical Spitz tumors, and Spitz melanomas, also referred to as malignant Spitz tumors (1). Based on the underlying genetic aberrations, Spitz melanocytic proliferations can be divided into four distinct groups: 1) 11p amplified/ HRAS mutated proliferations, 2) proliferations with tyrosine kinase fusions (ALK, ROS1, NTRK1, NTRK3, MET, RET), 3) proliferations with serine/ threonine kinase fusions $(M A P 3 K 8, B R A F)$ and 4) proliferations with Spitz morphology but lack- 
ing an $11 \mathrm{p} / H R A S$ mutation, kinase fusions, $B R A F$, NRAS, GNAQ, GNA11 mutations and other driver genetic changes characteristic of other defined melanocytic subgroups (1). The last group is at present poorly defined and will not be discussed further in this review. Importantly, driver genetic events are mutually exclusive in a particular Spitz melanocytic proliferation and are by themselves insufficient for the development of overt malignancy, generally characterized by the development of distant metastases and aggressive biological behavior $(2,3)$.

As has been demonstrated by recent studies, such a combined morphological/genetic classification better correlates with the biological behavior of different groups of Spitz melanocytic proliferations. The vast majority of Spitz melanomas resulting in distant metastatic spread harbor serine/ threonine kinase fusions (4-11). Furthermore, since several biological drugs are available to treat melanocytic proliferations with aggressive clinical behavior, the characterization of particular driver genetic events and additional genetic abnormalities is becoming increasingly important.

Herein, we review recent advances in the molecular genetics of Spitz melanocytic proliferations. Special emphasis is given to the correlation of molecular genetic aberrations with morphological features and with the biological behavior of Spitz melanocytic proliferations. Immunohistochemistry can be a reliable surrogate tool for certain molecular abnormalities to molecular genetic testing, as discussed further in this review (for practical purposes, the list of antibodies reflecting possible kinase fusions the authors are using routinely is summarized in the Table 1. Also, at the end of each

Table 1. The List of Antibodies Reflecting Possible Kinase Fusions Used Routinely by the Authors of the Current Review

\begin{tabular}{llll}
\hline Antigen & Clone & Manufacturer & Dilution \\
\hline ALK & 5A4 & $\begin{array}{l}\text { Leica Biosystems, } \\
\text { Wetzlar, Germany }\end{array}$ & 1:10 \\
\hline ROS1 & SP384 & $\begin{array}{l}\text { Ventana, Roche, Tucson, } \\
\text { USA }\end{array}$ & $\begin{array}{l}\text { RTU (Ready } \\
\text { To Use) }\end{array}$ \\
\hline panTRK & EPR17341 & Abcam, Cambridge, UK & 1:50 \\
\hline
\end{tabular}

section, a table is presented with short summary of key data for each particular Spitz group of melanocytic proliferations).

\section{1p Amplified and/or HRAS Mutated Spitz Melanocytic Proliferations}

The first recurrent genetic alterations discovered in Spitz melanocytic proliferations were $11 \mathrm{p}$ amplification and HRAS mutation. They were also the first genetic alterations associated with a specific morphologic phenotype in this group of melanocytic neoplasms $(12,13)$. Both $11 \mathrm{p}$ amplification and HRAS mutation can appear exclusively or simultaneously in a single lesion and are most commonly associated with a desmoplastic Spitz nevus morphology $(13,14)$. HRAS (Harvey rat sarcoma viral oncogene homolog) resides on $11 \mathrm{p}$ chromosome arm (11p15.5) and belongs to the Ras family of oncogenes, encoding a GTPase that is involved in cellular signaling (the MAP kinase-signaling pathway) $(15,16)$. Mutations in HRAS lead to constitutive activation of an altered protein that impacts the expression of various transcription factors involved in cell cycle progression, thus stimulating cell growth and differentiation (16). HRAS mutations have also been detected in urothelial and squamous cell carcinomas, adenocarcinomas of various origins, leukemias, and myelodysplastic syndromes (17-19). HRAS mutations in Spitz melanocytic proliferations are most commonly missense mutations involving codons 61 and 13, with the three most commonly reported mutations being Q61L $(2,6,14,20), Q 61 R(14,20-23)$, and $\operatorname{G13R}(6,21,24-28)$.

The prototypic $11 \mathrm{p}$ amplified/HRAS mutated Spitz nevus is a symmetrical, predominantly dermal, relatively hypocellular proliferation composed of large, epithelioid and spindled melanocytes with desmoplastic stromal reaction (i.e., thickened collagen fibers between single neoplastic cells) and an infiltrative base (Figure 1) (2, 13, 14). Melanocytes have abundant eosinophilic or amphophilic cytoplasm, vesicular nuclei, and mild to moderate nuclear pleomorphism $(2,13$, 14). The proliferation rate is usually low, although 

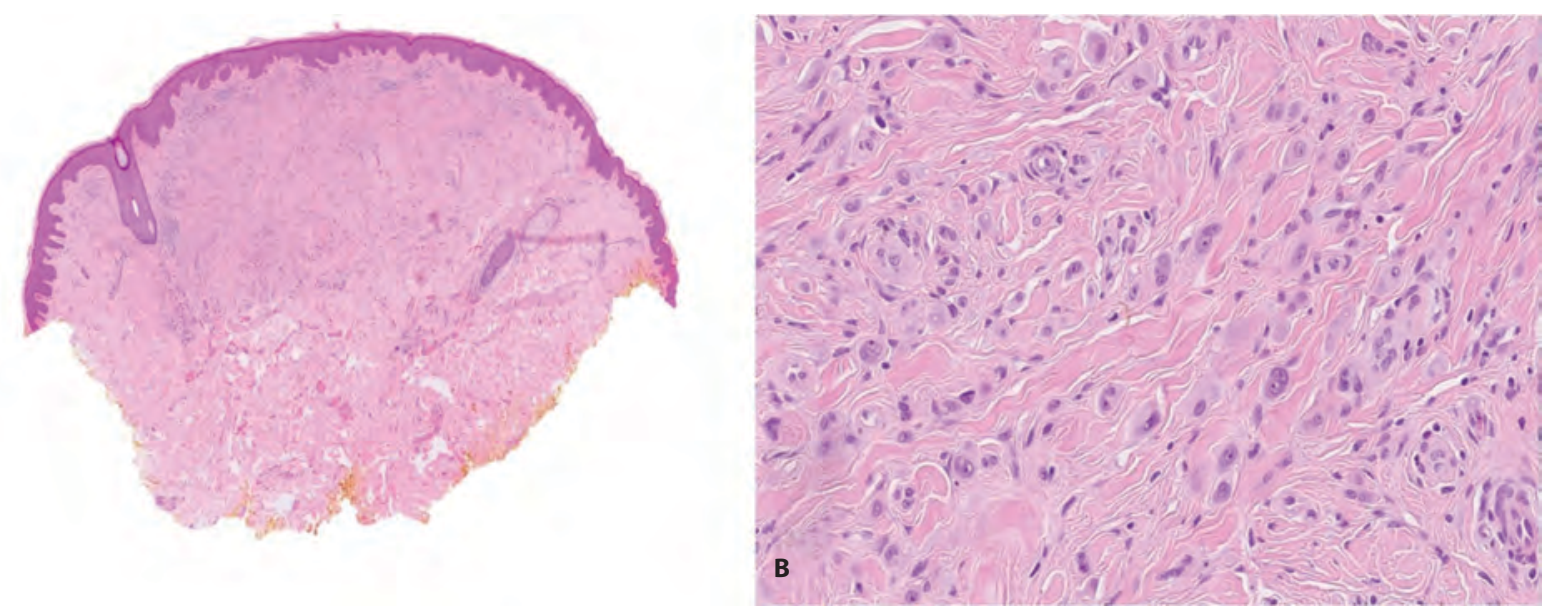

A

Figure 1. Desmoplastic Spitz nevus. A. Low power magnification reveals a fairly symmetrical intradermal proliferation with infiltrative growth pattern and a desmoplastic stromal reaction. B. Dense collagenous stroma containing epithelioid melanocytes with abundant eosinophilic cytoplasm with darkly stained nuclei and prominent nucleoli is typical for the entity.

isolated deep mitoses and, in rare instances, multiple mitoses may be present and are not associated with malignancy $(2,13,14,29)$. Atypical mitoses are generally absent.

In addition to solitary lesions with typical desmoplastic Spitz nevus morphology, other melanocytic proliferations with HRAS mutations and/or $11 \mathrm{p}$ gain have also been described, including agminated Spitz nevi with or without associated nevus spilus (25-28), recurrent Spitz nevi (30), melanocytic nevi with deep penetrating nevus-like morphology (21), pseudogranulomatous Spitz nevi (31) and a combination of syringocystadenoma papilliferum, tubular adenoma and a Spitz nevus (24). Moreover, the desmoplastic Spitz nevus phenotype is not restricted to HRAS mutated lesions since rare Spitz nevi harboring ROS1, ALK or even a $B R A F$ fusion exhibiting a desmoplastic Spitz nevus morphology have been described $(2,32)$.

Even though the vast majority of Spitz proliferations with HRAS mutations are essentially associated with benign clinical behavior $(14,29,33)$, there are occasional reports of HRAS mutated Spitz melanomas $(6,23)$. Recently, Raghavan et al. published a series of Spitz melanomas, two of which harbored HRAS hotspot mutations (23). Both lesions were associated with additional genetic aberrations, namely a loss of chromosome 9 (accompanied by negative p16 immunohistochemical reaction) in a case of a 50-year-old female, and a three-codon deletion in MAP2K1 (p.102_104del), a hemizygous mutation in ARID1A, homozygous deletion of CDKN2A and NOTCH2 amplification in a case of a 75-year-old female (23). Unfortunately, clinical follow-up was not available in either of the two cases (23). Lazova et al. also reported two melanomas with HRAS mutations in their series (6). One case was of a 73-year-old male diagnosed with Spitz melanoma that harbored an HRAS Q61L mutation, which developed metastases two years later, but he was still alive at a 4-year follow-up (6). The second case was a 60 -year-old male diagnosed with conventional melanoma that

Table 2. Spitz Melanocytic Proliferations with 11p Amplification/HRAS Mutation

\begin{tabular}{ll}
\hline Morphological & - Symmetrical, predominantly \\
features & intradermal, infiltrative base \\
& - Epithelioid and spindled melanocytes \\
& - Large \\
& - Abundant cytoplasm \\
& - Mild to moderate pleomorphism \\
& - Mitoses rare, can be deep \\
& - Low proliferation rate \\
& - Desmoplastic stromal reaction \\
\hline Biological behavior & Generally benign \\
\hline Confirmatory test & Next generation sequencing \\
& Fluorescence in situ hybridization (for \\
& $11 p$ amplification) \\
& Comparative genomic hybridization (for \\
& $11 \mathrm{p}$ amplification) \\
\hline
\end{tabular}


harbored an HRAS G13R mutation, who developed metastases two years later, and died at the age of 63 (6).

\section{Spitz Melanocytic Proliferations with Tyrosine Kinase Fusions}

\section{ALK Fusions}

The anaplastic lymphoma kinase $(A L K)$ gene resides on chromosome 2 p23 and encodes a tyrosine kinase receptor, a transmembrane protein that belongs to the insulin receptor family (34). Genetic alterations of the $A L K$ gene include point mutations, gene fusions, $A L K$ locus amplification, alternative transcription, and small deletions (35) and influence cell proliferation and survival via constitutive activation of the RAS-ERK, JAK3-STAT3, and PI3K-AKT-mTOR pathways (36-38). Fusions involving the $A L K$ gene have been discovered in diverse cutaneous neoplasms, including primary cutaneous anaplastic large cell lymphoma (39), epithelioid fibrous histiocytoma (40), acral melanomas $(41,42)$, and Spitz melanocytic proliferations $(2,43-50)$.

In Spitz melanocytic proliferations, various different fusion partners have been identified, including TPM3 (2, 11, 45, 51-54), DCTN1 (2, 23, 45, 50, 54), MLPH (9, 44, 45, 55), KANK1 $(9,45)$, CLIP1 (50), DDX3Y (9), EEF2 (45), GTF3C2 (50), MYO5A (45), NPM1 (47), PPFIBP1 (9), SPTAN1 (9) and TPR (50), in descending order of frequency. Lesions from the whole biological spectrum ranging from Spitz nevi, atypical Spitz tumors to Spitz melanomas have been distributed fairly equally among different fusion partners $(2,9,11$, $23,44,45,47,50-52,54-56)$. Although different fusions in Spitz melanocytic proliferations are generally believed to be mutually exclusive with BRAF mutations, a few examples (two Spitz melanomas, one atypical Spitz tumor, and an acral melanoma) with concurrent $A L K$ fusion and a BRAF mutation have been reported in the literature $(41,54,57)$. Such a combination of $A L K$ fusion and BRAF mutation is, nevertheless, exceptionally rare.
Spitz melanocytic proliferations with $A L K$ fusions have the largest average diameter among all Spitz melanocytic proliferations (43). The vast majority of Spitz proliferations with $A L K$ fusion are polypoid/dome and/or wedge-shaped solitary lesions with a bulbous and/or infiltrative base. They are composed of plexiform and intersecting fascicles of fairly large, fusiform/spindle cell or mixed spindle and epithelioid cell melanocytes with amphophilic cytoplasm and vesicular nuclei with prominent nucleoli (Figure 2) (2, 23, 43-46, 49, 50, $54,55,58)$. Nuclear pleomorphism is usually mild and occasionally moderate. Melanocytes may appear discohesive with clefts or small vesicle-like spaces in between $(23,50,55,59)$. Ulceration may be present, as may be dermal (even deep) mitoses and perineural invasion, but Kamino bodies are rare $(23,43,45,47,50,58)$. Melanin pigment is typically lacking or presents in limited amounts in the cytoplasm of melanocytes. Focal mucin deposits have been described (45). Proliferations with abundant myxoid areas with ALK+/SOX10+/ MelanA- spindle cells underneath the superficial nevoid or Spitzoid component have been termed melanocytic myxoid spindle cell tumors with $A L K$ rearrangement (MMySTAR) (56). They have been shown to harbor $A L K$ fusions with different fusion partners, namely FBXO28, NPAS2, PPFIBP1, and TPM3 (56). Interestingly, a single example of a desmoplastic Spitz nevus harboring a TPM3-ALK fusion has also been reported (2).

ALK immunohistochemistry is a reliable surrogate marker for molecular genetic techniques in cases with diffuse and strong immunopositivity in most melanocytes (Figure 2c) (2, 43-46, 50). In contrast, weak and focal or heterogeneous ALK staining has been demonstrated in non-Spitz melanocytic proliferations with ALK overexpression due to other molecular mechanisms (e.g., alternative transcription initiation that leads to the expression of a novel ALK isoform $\operatorname{ALK}^{\text {ATI }}(60,61)$ or in cases with chromosome 2p23 gain (62)), in rare cases of cellular blue nevi and in a single case of deep penetrating nevus (63).

Exceptionally rare examples of Spitz melanocytic proliferations with $A L K$ fusion have har- 

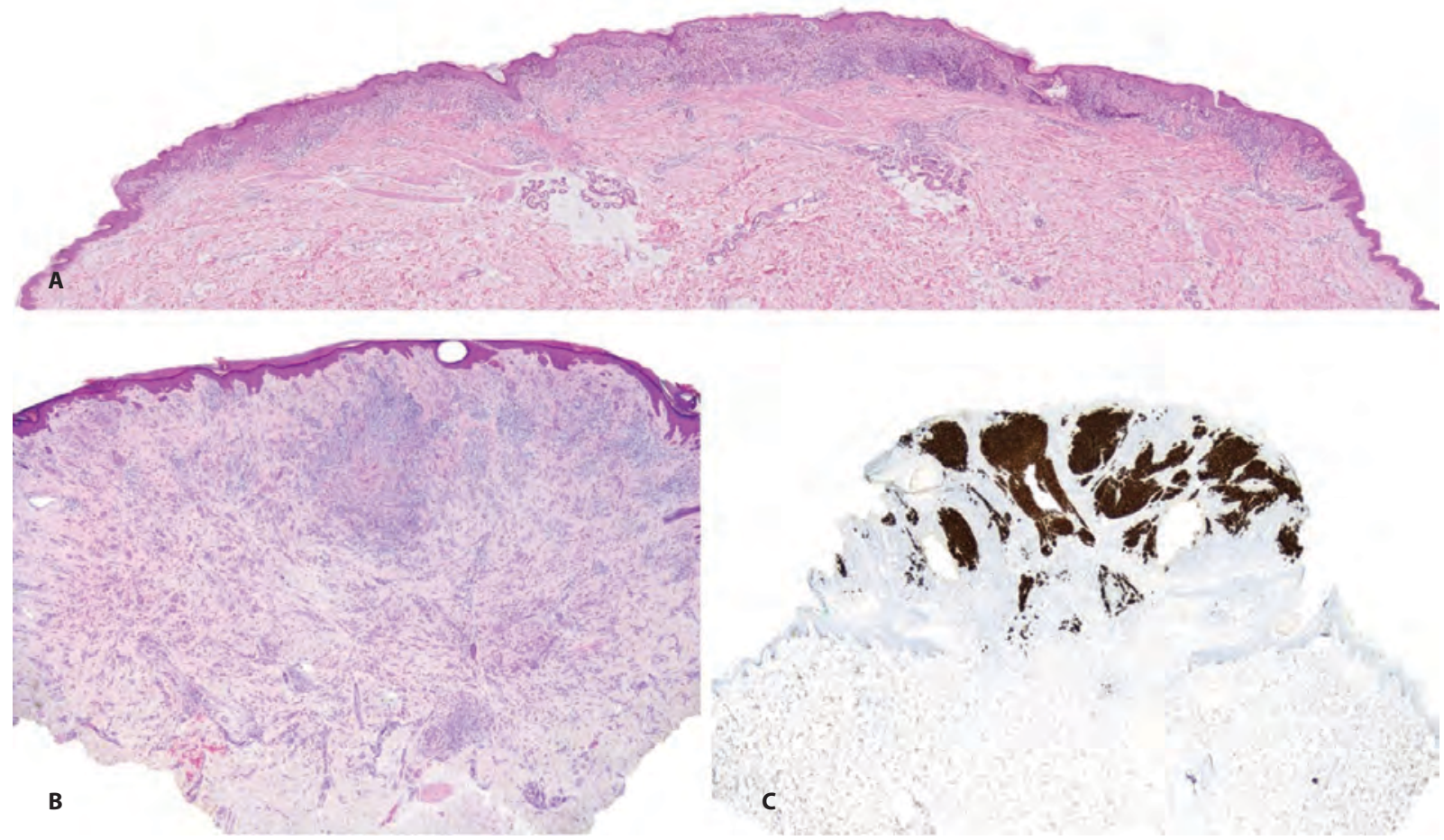

Figure 2. Spitz nevus with $A L K$ fusion. A. A large diameter of the proliferation is a characteristic feature of $A L K$-fused melanocytic proliferations. B. A plexiform growth pattern with deep extension of melanocytes is also frequently observed. $C$. ALK immunohistochemistry.

Table 3. Spitz Melanocytic Proliferations with ALK Fusions

\begin{tabular}{ll}
\hline Morphological & - Symmetrical, polypoid/dome and/or \\
features & wedge-shaped \\
& - Large diameter \\
& - Plexiform growth pattern \\
& - Epithelioid and spindled melanocytes \\
& - Mild to moderate pleomorphism \\
& - Mitoses rare \\
& - Pigmentation absent or scant \\
& - Low proliferation rate \\
& - Ulceration rare \\
& - Kamino bodies usually absent \\
\hline Biological behavior & $\begin{array}{l}\text { Generally favorable (benign) } \\
\text { Regional lymph node deposits } \\
\\
\text { uncommon } \\
\text { No distant metastases or death from the } \\
\text { disease }\end{array}$ \\
\hline Confirmatory test & - Immunohistochemistry \\
& - Next generation sequencing \\
& - Fluorescence in situ hybridization \\
\hline
\end{tabular}

bored additional molecular changes, i.e., homozygous 9p21 (CDKN2A) deletion in combination with 6p25 (RREB1) gain in two cases (49) and a hotspot TERT-promoter mutation (C228T) in one case (45), which had no effect on the biological behavior of the proliferation. Only two cases of Spitz melanocytic proliferations with $A L K$ fusion and with deposits in lymph nodes have been described, one of which had an additional homozygous 9p21 deletion $(49,55)$. Importantly, however, none of the cases of Spitz melanocytic proliferations with $A L K$ fusion and with available follow-up data were found to be associated with systemic metastases or death from the disease.

\section{ROS1 Fusions}

ROS1 protooncogene resides on chromosome 6q22.1 and, like $A L K$, encodes a protein receptor tyrosine kinase that is part of the intracellular signaling pathways Ras-Raf-MEK-ERK, JAK3STAT3, and PI3K-AKT-mTOR. (64) ROS1 fusions have been found in a variety of tumors, including non-small cell lung carcinomas, glioblastomas, pediatric gliomas, cholangiocarcinomas, inflamma- 


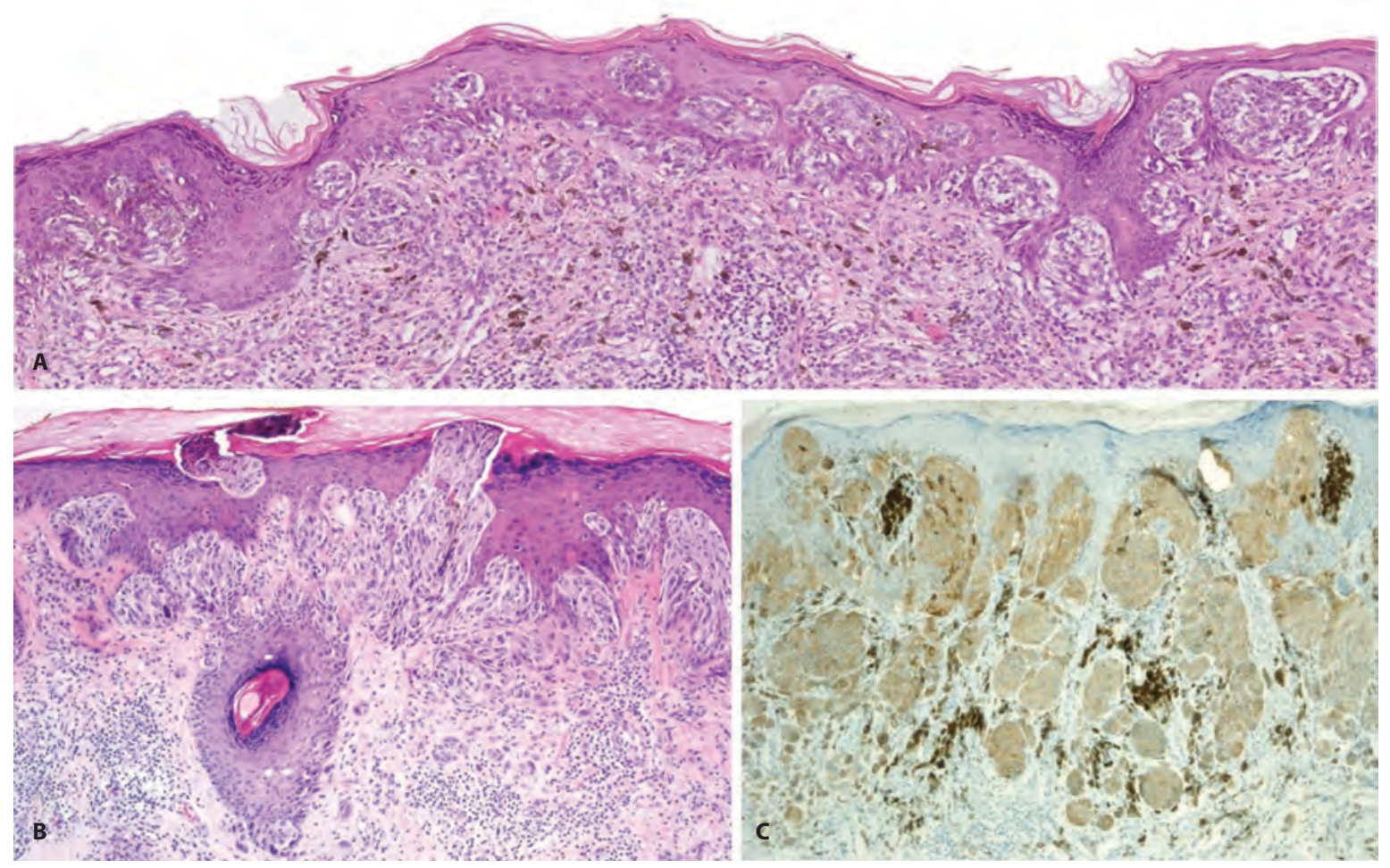

Figure 3. Spitz nevus with ROS1 fusion. A. ROS1-fused melanocytic proliferations often display a prominent junctional component. B. The junctional component consists of melanocytic nests with transepidermal elimination and colonization of the adnexal epithelium. C. ROS1 immunohistochemistry.

tory myofibroblastic tumors, etc (64). ROS1 fusions are present in up to $17 \%$ of Spitz melanocytic proliferations (2). Thirteen different fusion partners have been reported: $P W W P 2 A, T P M 3, P P F I B P 1$, CAPRIN1, MYO5A, PPFIBP1, CLIP1, ERC1, FIP1L1, HLA-A, KIAA1598, MYH9, and ZCCHC8, in descending order of frequency $(2,23,32,65)$.

Although ROS1-fused Spitz proliferations lack unique identifying morphological features, most ROS1-fused melanocytic proliferations are compound, composed either of spindle cells or of a combination of spindle and epithelioid cells with mild to moderate cytological atypia and with limited pigmentation of melanocytes $(2,32,65)$. The junctional melanocytic component is frequently prominent, with floating nests or trans-epidermal elimination of melanocytic nests, often colonizing the epithelium of skin adnexa (Figure 3) $(32,65)$. Kamino bodies seem to be more frequently present in ROS1 fused Spitz melanocytic proliferations, along with signs of maturation, lack of high-grade cytological atypia, lack of large cells, and fewer mitoses - all statistically significant features differing between ROS1 and non-ROS1 Spitz neoplasms in a study by Gerami et al. (32). Nonetheless, large cells were described in 9 of 11 ROS1 fused Spitz neoplasms in a study by Wiesner et al. (2), and up to 8 mitoses per square millimeter were reported in a study of such proliferations by Donati et al. (65)

Immunohistochemistry for ROS1 protein is a reliable surrogate for molecular testing (Figure 3c). Studies have confirmed that the vast majority (97.4\%) of Spitz melanocytic proliferations harboring ROS1 fusions display ROS1 cytoplasmic positivity on immunohistochemistry $(2,32)$. It is important to note, though, that immunohistochemical staining is often weak yet diffuse.

The vast majority of hitherto reported Spitz neoplasms with ROS1 fusion in the literature were classified as either Spitz nevi or atypical Spitz tumors $(2,23,32,47,65-67)$. Three lesions were of desmoplastic Spitz nevus phenotype $(2,32)$, four 
Table 4. Spitz Melanocytic Proliferations with ROS1 Fusions

\begin{tabular}{ll}
\hline Morphological & - Junctional component prominent \\
features & - Transepidermal elimination of nests \\
& - Adnexal involvement \\
& - Epithelioid and spindled melanocytes \\
& - Mild to moderate pleomorphism \\
& - Mitoses rare \\
& - Pigmentation limited \\
& - Low proliferation rate \\
& - Maturation present
\end{tabular}

were pigmented spindle cell nevi or Reed nevi (2, 67 ), and one was an eruptive Spitz nevus (48). The last was reported in a 49-year old female, who developed over 100 similar lesions over four years. Further molecular characterization of the proliferation revealed identical TPM3-ROS1 fusions in the three analyzed lesions (48). Only five Spitz melanomas with ROS1 fusion have been described, and none of them resulted in distant metastases or death from the disease $(2,47)$.

\section{NTRK Fusions}

Neurotrophic tyrosine kinase receptor genes NTRK1, NTRK2 and NTRK3, are oncogenes encoding the Trk family of tyrosine kinase receptors (TrkA, TrkB, and TrkC, respectively) (68). These tyrosine kinase receptors are all single-pass transmembrane enzymes that stimulate different pathways once activated, namely the MAPK/ERK, PI3K-AKT-mTOR, and phospholipase C- $\gamma$ pathways $(3,68)$. In most NTRK fusions identified, the 3 ' portion encoding the kinase domain is retained, and the 5' portion encoding dimerization domains is provided by the fusion partner. The resultant chimeric Trk protein is an oncogenic, constitutively active tyrosine kinase (69).

In Spitz melanocytic proliferations, NTRK1 fusions predominate over NTRK3 fusions, the latter being more common in the pigmented spindle cell nevus of Reed, a special subtype of Spitz nevus (2, $9,11,23,43,46,47,67,69-74)$. Only a single case of superficial spreading melanoma with an TRAF2NTRK2 fusion has been reported so far (7).

The NTRK1 fusion partners in Spitz melanocytic proliferations include LMNA $(2,9,72)$, TPM3 $(11,23,47,72)$, TP53 (2, 72), and KHDRBS1 (9, $72)$, in descending order of frequency. Even though the number of cases for each particular known NTRK1 fusion partner is relatively low (LMNA was identified in 16 cases, while TP53 and KHDRBS1 in two cases each), 4 of 5 Spitz melanocytic proliferations with TPM3-NTRK1 fusion were diagnosed as Spitz melanomas, all with several additional chromosomal aberrations, including (most commonly) homozygous deletions of CDKN2A (11, $23,47,72)$. Furthermore, Spitz melanoma was also diagnosed in one of the two reported cases with an KHDRBS1-NTRK1 fusion $(9,72)$.

Four different fusion partners have been identified so far for NTRK3 fusions, namely MYO5A (67, 69, 70, 73), ETV6 (67, 70, 73), MYH9 (70, 73), and SQSTM1 (9), in descending order of frequency. While no NTRK1 fusions have been identified in Reed nevi, they harbor NTRK3 fusions (with MYO5A and rarely ETV6 fusion partners) in up to $57 \%$ of cases (67). In addition to pigmented spindle cell nevi of Reed, Spitz proliferations with NTRK3 fusions are usually diagnosed as Spitz nevi or atypical Spitz tumors and much less frequently as Spitz melanomas $(9,67,69,70,73)$.

NTRK1 and NTRK3 fusions are also occasionally detected in non-Spitz melanocytic proliferations, e.g., pigmented epithelioid melanocytomas $(75,76)$, acral melanomas $(42)$, and in a wide variety of non-melanocytic tumors, e.g., infantile fibrosarcoma, secretory carcinoma of the breast, secretory carcinoma of the salivary gland, congenital mesoblastic nephroma, lung carcinoma, thyroid papillary carcinoma and high grade gliomas (77).

Histologically, NTRK1-fused Spitz melanocytic proliferations are characterized by filigree-like rete ridges (elongated, thin rete ridges), lobulated dermal melanocytic nests (composed of smaller nests inside the larger ones), and by the formation of 


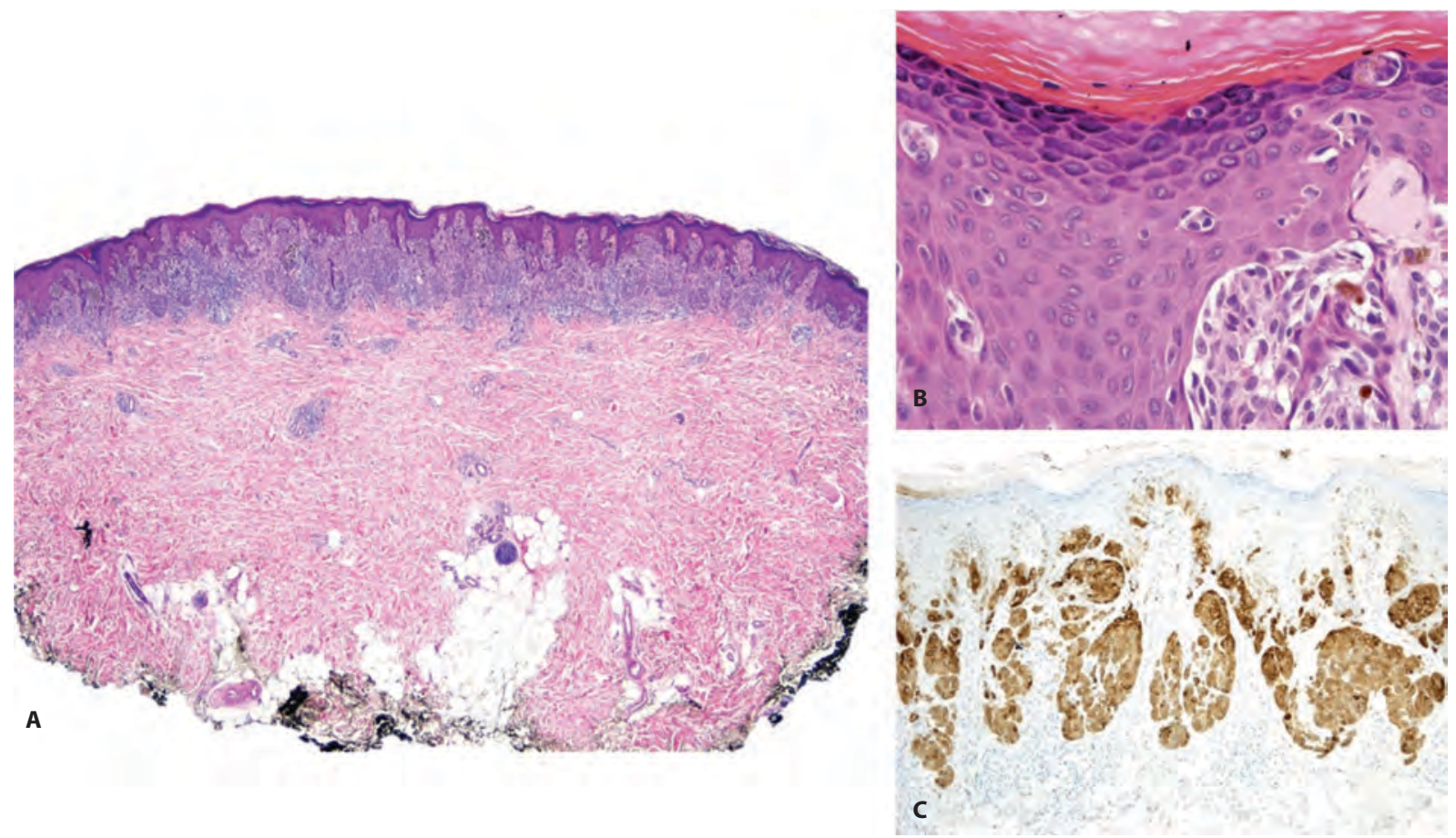

Figure 4. Spitz nevus with NTRK fusion. A. A symmetrical compound melanocytic proliferation associated with hyperplasia of the epidermis is depicted in this photo. B. Kamino bodies are often numerous in NTRK1-fused Spitz melanocytic proliferations. C. pan-TRK immunohistochemistry.

pseudorosettes $(23,43,72)$. Exaggerated maturation of spindled and/or epithelioid melanocytes displaying mild to moderate nuclear pleomorphism is also a characteristic finding $(23,43,72)$. Mild to moderate and sometimes even marked lymphocytic infiltrate is often present $(2,46,72)$. While the pagetoid spread of melanocytes has been observed in up to $25 \%$ of cases, Kamino bodies are variably present (Figure 4) $(2,43,46,72)$. NTRK1 fused Spitz melanocytic proliferations can occasionally resemble those with ALK fusions, exhibiting an intersecting fascicular growth pattern in the dermis (46).

Pigmented spindle cell nevus of Reed is a prototype of Spitz melanocytic proliferation harboring an NTRK3 fusion (67). While MYO5A-NTRK3 fusions are the most common driver genetic aberrations in this subgroup of Spitz nevi, NTRK1 fusions are generally absent (67). It has been recently demonstrated that various NTRK3 fusion partners have different intracellular localizations, ultimately determining the morphological characteristics of the Spitz melanocytes (62). For exam- ple, MYO5A-NTRK3 chimeric protein is localized to cell dendritic processes and is associated with a fusiform/spindled morphology of melanocytes with a fascicular or sometimes plexiform or syncytial growth pattern (70). Besides, the formation of pseudo-Verocay bodies or pseudorosettes is associated with a more neuroid appearance of these proliferations (70). In contrast, the ETV6-NTRK3 chimeric protein is localized to both the nucleus and cytoplasm of melanocytes and is linked to an epithelioid morphology with well-defined cell borders. Melanocytes have abundant, glassy cytoplasm and somewhat large, pleomorphic nuclei. They are arranged in large coalescing and also lobulated nests. Signs of maturation are fairly discrete (70). Finally, Spitz melanocytic proliferations with MYH9-NTRK3 fusion are distinguished by fibrotic stroma and peripheral collagen trapping (70).

Immunohistochemistry with pan-TRK antibody can be used to detect the fusion protein (Figure 4c). Both available clones, clone A7H6R (Cell Signaling Technology) and EPR17341 (Abcam/Ventana) are highly sensitive and specific, 
EPR17341 being slightly superior in terms of specificity (78). The staining pattern can hint at the presence of the NTRK fusion subtype. However, most pan-TRK immunohistochemistry studies in different NTRK fusion subtypes were performed on mostly non-Spitz NTRK-fused tumors $(79,80)$. Pan-TRK immunohistochemical staining is more intense and cytoplasmic in NTRK1-fused tumors, with additional nuclear accentuation in cases with an LMNA-NTRK1 fusion $(79,80)$. On the other hand, up to $50 \%$ of tumors with an NTRK3 fusion exhibit a cytoplasmic and nuclear pan-TRK immunohistochemical reaction $(79,80)$. However, a study by de la Fouchardière et al., which included only NTRK3-fused Spitz melanocytic proliferations, demonstrated that more intense nuclear and less intense cytoplasmic immunoreactivity is indicative of an ETV6-NTRK3 fusion. At the same time, linear staining along dendritic processes can point to the presence of an MYO5A-NTRK3 fusion (70).

Exceptional cases of non-Spitz ('spitzoid') melanomas with NTRK fusions have been reported resulting in widespread hematogenous metastases (7). In contrast, Spitz melanomas with NTRK fusions do not carry a dismal prognosis since only rare metastases to lymph nodes, but not beyond, have been described $(47,71)$. At present, no examples of Spitz melanocytic proliferations with

Table 5. Spitz Melanocytic Proliferations with NTRK1 Fusions

\begin{tabular}{ll}
\hline Morphological & - Filigree-like rete ridges \\
features & - Lobulated melanocytic nests \\
& - Rosette-like structures \\
& - Extreme maturation \\
& - Epithelioid and spindled melanocytes \\
& - Mild to moderate pleomorphism \\
& - Mitoses rare \\
& - Kamino bodies frequent
\end{tabular}

NTRK fusions and with distant metastases or death from the disease have been reported. In the unlikely event of an NTRK-fused metastatic Spitz melanoma, specific therapy with TRK inhibitors is available $(81,82)$.

\section{RET Fusions}

The RET protooncogene resides on chromosome 10q11.21 and encodes a protein receptor tyrosine kinase involved in the MAPK/ERK, PI3K/AKT/ mTOR and phospholipase $\mathrm{C}-\gamma 1$ intracellular signaling pathways (2). Only a handful of Spitz melanocytic proliferations with RET fusions have been reported $(2,9,43,67,83)$. Four different fusion partners have been identified: CCDC6 (9), GOLGA5 (2), KIF5B (2), and MYO5A (67). Similar fusions have also been detected in thyroid cancer (84) and lung adenocarcinomas (85).

RET fusions have been reported in the whole biological spectrum of Spitz melanocytic proliferations, including ordinary Spitz nevi and pigmented spindle cell nevus of Reed, atypical Spitz tumors, and Spitz melanomas (2, 9, 43, 67, 83). Although the morphologic features of RET fused Spitz melanocytic proliferations lack specificity, such proliferations are often well-circumscribed, symmetrical, compound melanocytic proliferations with a plaque-like silhouette, a nested growth pattern of small to intermediate-sized epithelioid and spindled melanocytes with only mild cytological atypia $(2,43,67)$.

RET-fused Spitz melanocytic proliferations generally follow an indolent clinical course $(2,9$, $43,67,83)$. At present, no Spitz melanomas with RET fusion and a dismal outcome have been reported in the literature $(2,9,43,67,83)$. Nevertheless, in the unlikely event of aggressive clinical behavior, potential therapy with RET inhibitors is available (2).

\section{MET Fusions}

The MET protooncogene is localized on chromosome 7q31.2 and encodes a tyrosine kinase receptor with high affinity for hepatocyte growth factor 
(86). Only eight Spitz melanocytic proliferations, including a Spitz nevus, five atypical Spitz tumors, and two Spitz melanomas with MET fusions, have been reported $(74,83,86)$. The largest series of six Spitz neoplasms with MET fusions demonstrated a breakpoint in intron 14 in all of the cases (86). The breakpoint event is localized upstream of the kinase domain-encoding exons 15 to 21 , which are fully retained. In contrast, the auto-inhibitory domain encoded in exon 14 is absent in the chimeric protein (86). The $\mathrm{N}$-terminal fusion partners identified in their series were ZKSCAN1, PPFIBP1, TRIM4, LRRFIP1, EPS15, and DCTN1 (86).

$M E T$ fusions result in constitutive activation of tyrosine kinase with subsequent activation of the MAPK/ERK, PI3K/AKT/mTOR, and phospholipase C- $\gamma 1$ pathways, which can be inhibited by cabozantinib (inhibitor of c-MET and VEGFR2) or PF-04217903 (c-MET inhibitor) (86). The number of reported Spitz melanocytic proliferations with MET fusions is too small to conclude specific morphologic features and prognosis. However, none of the cases with available follow-up resulted in aggressive clinical behavior (86).

\section{Spitz Melanocytic Proliferations with Serine/Threonine Kinase Fusions}

The largest proportion of Spitz melanocytic proliferations with serine/threonine kinase fusions involves the MAP $3 K 8$ or BRAF genes. Nevertheless, other serine/threonine kinase fusions involving the $R A F 1, P R K C A / B$, and $A R A F$ genes have exceptionally been reported in a few examples of atypical Spitz tumors and Spitz melanomas $(9,83)$. Notably, the vast majority of Spitz melanocytic proliferations with serine/threonine kinase fusions are classified as atypical Spitz tumors or Spitz melanomas and are infrequently detected in Spitz nevi.

\section{MAP3K8 Fusions}

Mitogen-activated protein kinase kinase kinase 8 (MAP3K8), also known as Tpl-2 and COT, is an enzyme belonging to the group of serine/threo- nine protein kinases $(87,88)$ and is encoded by the $M A P 3 K 8$ gene that resides on chromosome 10p11. The enzyme consists of a kinase domain encoded by exons 1-8 of the MAP3K8 gene and an inhibitory C-terminal domain encoded by exon 9 of the MAP3K8 gene. The inhibitory C-terminal domain covers the kinase domain in its inactive state, preventing it from phosphorylating MEK proteins. The inhibitory C-terminal domain is also essential for targeting the MAP3K8 enzyme for proteolytic degradation. Fusions involving the MAP $3 K 8$ gene and truncation of the MAP $3 K 8$ gene follow the same basic mechanism, resulting in a fusion/truncated transcript including the intact kinase domain while lacking the inhibitory C-terminal domain. Consequently, kinase activity is unopposed by the C-terminal inhibitory action and, at the same time, the MAP3K8 is not targeted for proteolytic degradation, resulting in significant MAP3K8 overexpression and increased phosphorylation of MEK proteins, which in turn phosphorylate and activate ERK1/2 proteins that influence cell proliferation, division and differentiation (88-90). Similarly, one of the MEK proteins (MAP2K1, also called MEK1) has an autoinhibitory domain in amino acids 98 to 104, and deletions in this region (e.g., p.I103_K104del of MAP2K1) also result in constitutive activation of downstream ERK1/2 proteins (91).

A number of different $M A P 3 K 8$ fusion partners have been identified, including SVIL (9, 23, 92, 93), DIP2C (53, 83, 91, 92), UBL3 (9, 83, 92), SPECC1 (9, 92), STX7 (9, 92), ATP2A2 (91), CCNY (92), CDC42EP3 (92), CUBN (92), GNG2 (9), LINC00703 (92), MIR3681HG (92), PCDH7 (91), PIP4K2A (92), PRKACB (9), SFMBT2 (92), SLC4A4 (92), SUBN (9) and ZFP36L1 (23).

$M A P 3 K 8$ fusions and truncations have also been identified in ovarian, lung, and breast carcinomas, mesotheliomas, cutaneous myxoinflammatory fibroblastic sarcoma, squamous cell carcinomas, and melanocytic tumors - in rare acral melanomas and Spitz neoplasms (9, 23, 53, 83, 92-97).

Morphologically, Spitz proliferations with a MAP3K8 fusion are often ulcerated tumors (more than $50 \%$ ) with predominantly epithelioid mor- 

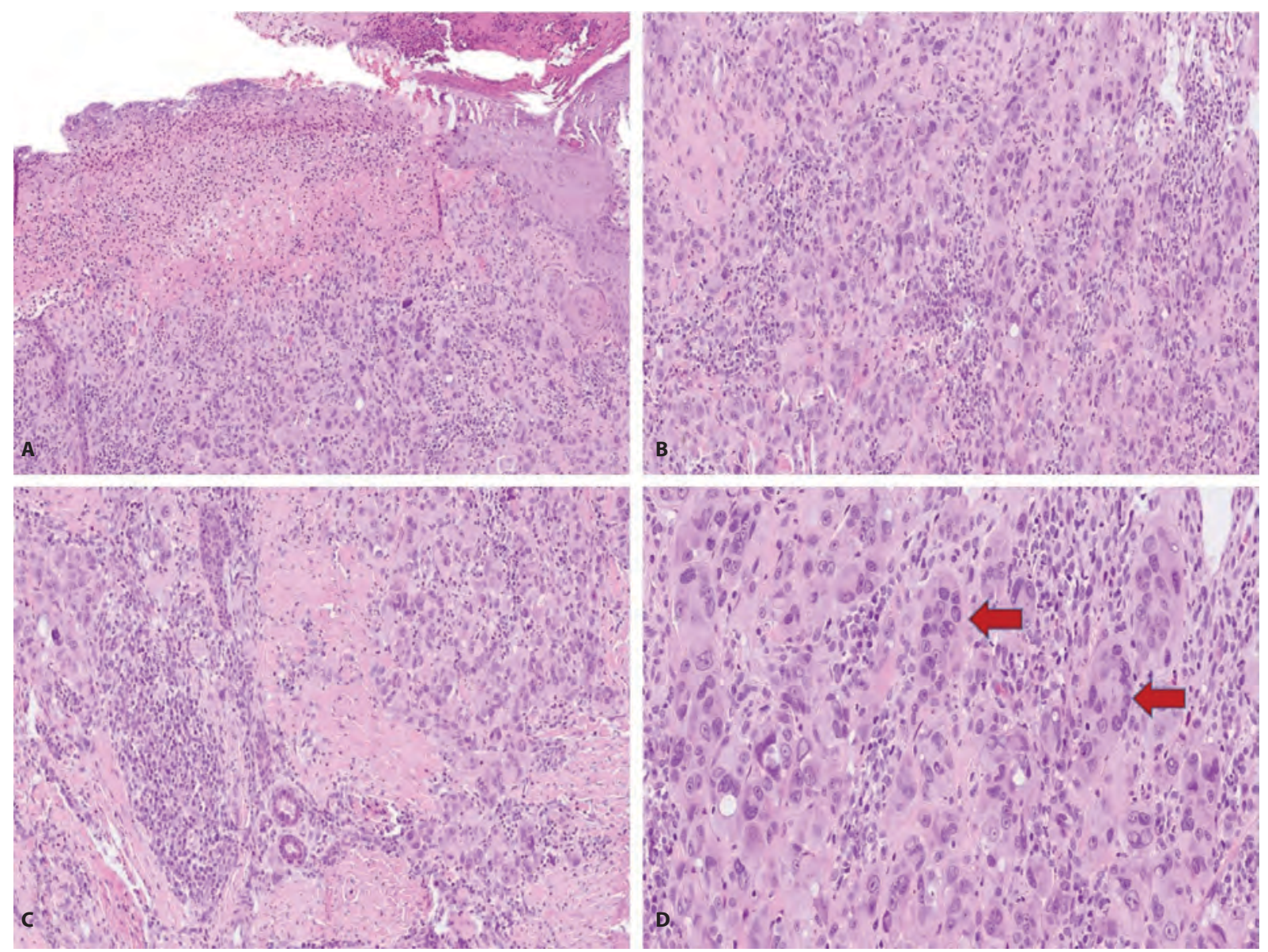

Figure 5. Atypical Spitz tumor. A. This is an example of an ulcerated Spitz melanocytic tumor. B. The lesion is composed of epithelioid melanocytes with moderate cytological atypia. C. No maturation is present. D. Large multinucleated giant melanocytes (arrows) can be a morphological clue for the presence of MAP3K8 fusion.

phology, moderate to pronounced cytological atypia, and generally lack maturation (Figure 5). Additional characteristic features include focal hyperpigmented dermal clones and giant multinucleated melanocytes. Deep mitotic activity is not uncommon $(9,23,53,91,92)$. Furthermore, desmoplastic stromal reaction and focal pagetoid scatter can be seen in $73 \%$ and $45 \%$ of cases, respectively (92).

A literature review revealed that most Spitz proliferations with $M A P 3 K 8$ fusion or truncations, a MAP3K3 fusion, and a MAP2K1 p.I103_K104del were classified either as atypical Spitz tumors or Spitz melanomas (40\% and 52\%, respectively). In comparison, Spitz nevi represented only a small portion (8\%) of cases in this Spitz subgroup (23,
53, 91, 92, 98). Houlier et al. reported the largest series of 33 cases of Spitz melanocytic proliferations with MAP3K8 fusions, of which 13 (40\%) were classified as atypical Spitz tumors and 15 (45\%) as Spitz melanomas (92). Moreover, $77 \%$ of these atypical Spitz tumors and Spitz melanomas harbored CDKN2A (92) inactivation, which was also reported as one of the most common secondary genetic events in some other series $(23,83,91)$. The biological behavior of Spitz melanocytic proliferations with a MAP3K8 fusion is variable; it appears that the prognosis depends on the presence of these additional genetic aberrations. Biallelic inactivation of $C D K N 2 A$, demonstrated either by p16 immunohistochemistry (with focal or diffuse complete loss of p16 expression) or molecular ge- 
Table 6. Spitz Melanocytic Proliferations with MAP3K8 Fusions

\begin{tabular}{ll}
\hline Morphological & - Ulceration common \\
features & - Epithelioid morphology \\
& - Moderate to high grade cytological \\
& atypia \\
& - Lack of maturation \\
& - Mitoses not uncommon \\
& $\cdot$ Giant multinucleated melanocytes \\
& - Focal hyperpigmented dermal clones \\
\hline Biological behavior & $\begin{array}{l}\text { Mostly in atypical Spitz tumors and Spitz } \\
\text { melanomas }\end{array}$ \\
\hline Confirmatory test & - Next generation sequencing \\
& - Fluorescence in situ hybridization \\
\hline
\end{tabular}

netic techniques, has been detected in about 35\% of all reported cases of this MAP3K8 fused Spitz subgroup of melanocytic proliferation $(23,83,91$, 92), followed by TERT promotor mutations and a complex TERT structural rearrangement, albeit less frequently $(9,83)$.

A single case has been reported that resulted in the death of an 11-year old boy, who was diagnosed as having a Spitz melanoma with MAP3K8GNG2 fusion, additional complex structural rearrangement in the TERT gene, and a homozygous CDKN2A/B deletion (9). Three other Spitz melanomas with $M A P 3 K 8$ fusions, all three with additional biallelic CDKN2A inactivation, demonstrated tumor cells' deposits in at least one lymph node. However, none of these cases resulted in widespread metastatic disease during the 6 to 18 months follow up period $(91,92)$. Two atypical Spitz tumors with MAP3K8 fusions locally recurred, with otherwise no signs of distant metastases $(83,91)$.

\section{BRAF Fusions}

The BRAF gene encoding a serine-threonine protein kinase is composed of three highly conserved regions (CRs) $(99,100)$. CR1 contains $\mathrm{N}$-terminal RAS-binding and cysteine-rich domains, while CR2 contains serine-threonine-rich domains, and both CR1 and CR2 act as auto inhibitors of CR3, the kinase domain $(99,100)$. In $B R A F$ fusions, the resulting chimeric protein retains only the intact kinase domain (CR3) of the BRAF gene. The loss of autoinhibitory domains results in increased kinase activity, evidenced by increased phosphorylation and activation of downstream MEK1/2 and ERK1/2 proteins $(4,5)$.

Numerous fusion partners have been identified: AKAP9 (9, 10, 101), AGK (10, 102), CLIP2 (102, 103), BAIAP2L1 (11, 47), CEP89 (2), CUX1 (10), DYNC1/2 (10), EML4 (11, 47), LSM14A (2), MAD1L1 (9), MLANA (102), MYO5A (102), MZT1 (10), NRF1 (23), SKAP2 (102), SLC12A7 (10), SOX6 (23), TRIM24 (10) and ZKSCAN1 (10). In non-Spitz melanoma subtypes, additional fusion partners have been identified, such as KIAA1549 in a case of an acral melanoma (8), ZNF767 in two cases of mucosal melanomas $(5,10)$, PPFIBP2 in a case of superficial spreading melanoma (8), GTF2I in a metastatic melanoma of unknown primary origin (10), AGAP3, CCDC91, CDC27, PAPSS1, $R A D 18$ and TAX1BP1 in melanomas either classified as non-Spitz (spitzoid) or unclassified $(4,10)$.

Similar to the MAP3K8 fused Spitz subgroup of melanocytic proliferations, the vast majority of Spitz melanocytic proliferations with $B R A F$ fusion cluster towards the malignant end of the biological spectrum, with roughly $45 \%$ of published Spitz melanocytic proliferations with BRAF fusion belonging to atypical Spitz tumor, $41 \%$ to Spitz melanoma and only $14 \%$ to Spitz nevi $(2,9-11,23,43$, $47,71,74,83,101-103)$.

$B R A F$ fusions are present in various tumors, including gliomas, thyroid, and pancreatic carcinomas, non-small cell lung adenocarcinomas, and colorectal carcinomas (10).

Secondary genetic alterations in $B R A F$ fused Spitz melanocytic proliferations were similar to those in other Spitz subgroups. The most common secondary changes were the homozygous deletion of 9p21, TERT promoter mutations, 6p25 gains, and, in single cases, MDM2 amplification and ARID2 p.Q720 mutation (11, 43, 47, 101-103).

Histologically, BRAF fused Spitz melanocytic proliferations are predominantly dermal tumors composed of epithelioid or mixed, epithelioid and spindled melanocytes with vesicular nuclei and prominent nucleoli, with moderate to high-grade cytological atypia and somewhat amphophilic 

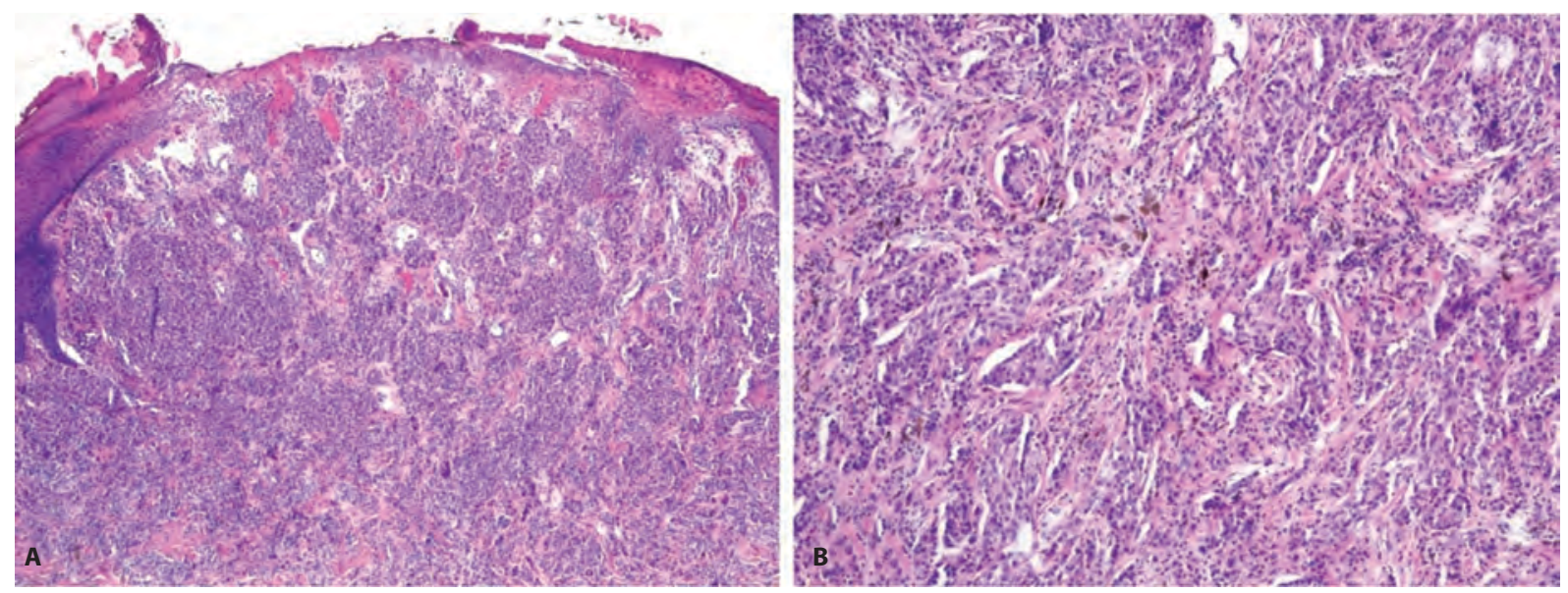

Figure 6. Atypical Spitz tumor. A. Low power magnification depicting an ulcerated melanocytic proliferation composed of epithelioid melanocytes. B. Epithelioid melanocytes with desmoplastic stromal reaction. Although such morphological changes can be seen in BRAF-fused Spitz melanocytic proliferations, they lack specificity.

Table 7. Spitz Melanocytic Proliferations with BRAF Fusions

\begin{tabular}{ll}
\hline Morphological & - Epithelioid morphology \\
features & - Moderate to high grade cytological \\
& atypia \\
& - Lack of maturation \\
& - Mitoses not uncommon \\
& - Desmoplasia at base \\
\hline Biological behavior & $\begin{array}{l}\text { Mostly in atypical Spitz tumors and Spitz } \\
\text { melanomas }\end{array}$ \\
\hline Confirmatory test & - Next generation sequencing \\
& - Fluorescence in situ hybridization \\
\hline
\end{tabular}

cytoplasm (11, 23, 43, 101-103). Interestingly, some authors have described a common, distinct growth pattern comprising of densely cellular sheet-like proliferation in the superficial part of the lesion, overlying a less cellular, desmoplastic base with prominent dermal sclerosis (Figure 6) $(2,43,101,102)$.

Widespread metastatic disease (i.e., metastases beyond the sentinel lymph node) has been described in 19 patients with melanomas with $B R A F$ fusion $(4,5,8,10,11,47)$, ten of which were called Spitz melanomas $(10,11,47)$. One case of nonSpitz metastasizing melanoma in a 54-year-old male harbored a BRAF V600E mutation and an $A G A P 3-B R A F$ fusion (10). Another case reported as a Spitz melanoma harbored concurrent $B R A F$ fusion, NRAS mutation, and a TERT promoter mutation (83).

\section{Conclusion}

Spitz melanocytic proliferations are defined by distinctive morphological and molecular genetic features. They encompass the whole biological spectrum of proliferations ranging from Spitz nevi, atypical Spitz tumors to Spitz melanomas. While most Spitz nevi can be reliably diagnosed on morphological grounds alone, additional molecular genetic testing is generally necessary to classify atypical Spitz tumors and Spitz melanomas and, significantly, to predict their biological behavior. The proposed algorithm of how to approach Spitz melanocytic proliferations is summarized in Figure 7. Molecular testing includes the detection of different driver fusions and additional genetic events associated with biologic behavior. In addition, since several biological drugs are available to treat melanocytic proliferations with aggressive clinical behavior, characterization of particular driver genetic events and additional genetic abnormalities is becoming increasingly important. 

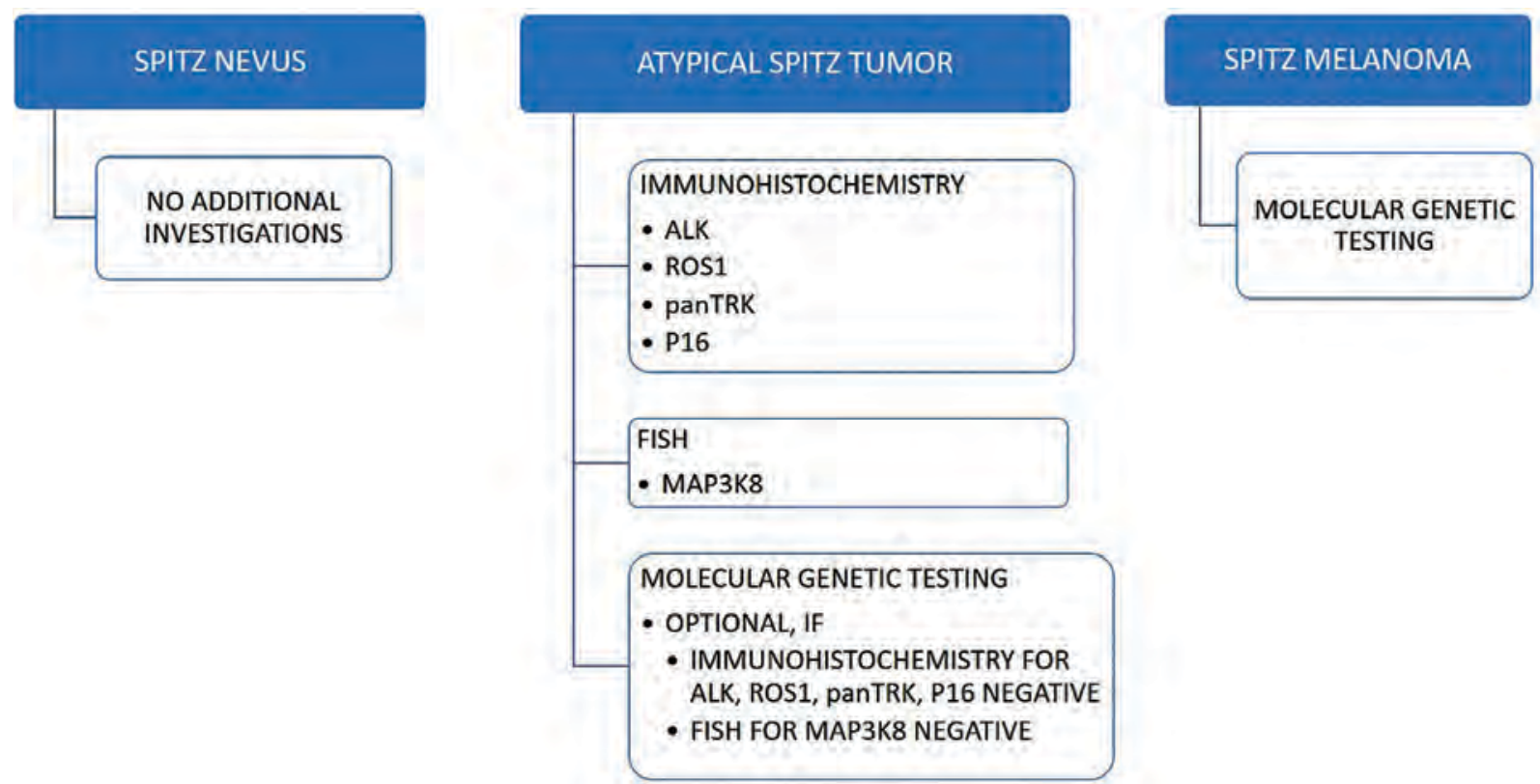

Figure 7. Proposed algorithm for diagnostic work-up of Spitz melanocytic proliferations.

Conflict of Interest: The authors declare that they have no conflict of interest.

\section{References}

1. Elder DE, Massi D, Scolyer RA, Willemze R, editors. WHO Classification of Skin Tumours. 4th ed. Lyon: International Agency for Research on Cancer; 2018.

2. Wiesner T, He J, Yelensky R, Esteve-Puig R, Botton T, Yeh $\mathrm{I}$, et al. Kinase fusions are frequent in Spitz tumours and spitzoid melanomas. Nat Commun. 2014;5:3116.

3. Wiesner T, Kutzner H, Cerroni L, Mihm MC Jr, Busam KJ, Murali R. Genomic aberrations in spitzoid melanocytic tumours and their implications for diagnosis, prognosis and therapy. Pathology. 2016;48(2):113-31.

4. Hutchinson KE, Lipson D, Stephens PJ, Otto G, Lehmann $\mathrm{BD}$, Lyle PL, et al. BRAF fusions define a distinct molecular subset of melanomas with potential sensitivity to MEK inhibition. Clin Cancer Res. 2013;19(24):6696-702.

5. Kim HS, Jung M, Kang HN, Kim H, Park CW, Kim SM, et al. Oncogenic BRAF fusions in mucosal melanomas activate the MAPK pathway and are sensitive to MEK/ PI3K inhibition or MEK/CDK4/6 inhibition. Oncogene. 2017;36(23):3334-45.

6. Lazova R, Pornputtapong N, Halaban R, Bosenberg M, Bai Y, Chai H, et al. Spitz nevi and Spitzoid melanomas: exome sequencing and comparison with conventional melanocytic nevi and melanomas. Mod Pathol. 2017;30(5):640-9.
7. Lezcano C, Shoushtari AN, Ariyan C, Hollmann TJ, Busam KJ. Primary and Metastatic Melanoma With NTRK Fusions. Am J Surg Pathol. 2018;42(8):1052-8.

8. Menzies AM, Yeh I, Botton T, Bastian BC, Scolyer RA, Long GV. Clinical activity of the MEK inhibitor trametinib in metastatic melanoma containing BRAF kinase fusion. Pigment Cell Melanoma Res. 2015;28(5):607-10.

9. Newman S, Fan L, Pribnow A, Silkov A, Rice SV, Lee S, et al. Clinical genome sequencing uncovers potentially targetable truncations and fusions of MAP3K8 in spitzoid and other melanomas. Nat Med. 2019;25(4):597-602.

10. Ross JS, Wang K, Chmielecki J, Gay L, Johnson A, Chudnovsky J, et al. The distribution of BRAF gene fusions in solid tumors and response to targeted therapy. Int J Cancer. 2016;138(4):881-90.

11. Wu G, Barnhill RL, Lee S, Li Y, Shao Y, Easton J, et al. The landscape of fusion transcripts in spitzoid melanoma and biologically indeterminate spitzoid tumors by RNA sequencing. Mod Pathol. 2016;29(4):359-69.

12. Bastian BC, Wesselmann U, Pinkel D, Leboit PE. Molecular cytogenetic analysis of Spitz nevi shows clear differences to melanoma. J Invest Dermatol. 1999;113(6):10659.

13. Bastian BC, LeBoit PE, Pinkel D. Mutations and copy number increase of HRAS in Spitz nevi with distinctive histopathological features. Am J Pathol. 2000;157(3):96772 .

14. van Engen-van Grunsven AC, van Dijk MC, Ruiter DJ, Klaasen A, Mooi WJ, Blokx WA. HRAS-mutated Spitz tumors: A subtype of Spitz tumors with distinct features. Am J Surg Pathol. 2010;34(10):1436-41. 
15. Maldonado JL, Timmerman L, Fridlyand J, Bastian BC. Mechanisms of cell-cycle arrest in Spitz nevi with constitutive activation of the MAP-kinase pathway. Am J Pathol. 2004;164(5):1783-7.

16. Ross AL, Sanchez MI, Grichnik JM. Molecular nevogenesis. Dermatol Res Pract. 2011;2011:463184.

17. Bos JL. ras oncogenes in human cancer: a review. Cancer Res. 1989;49(17):4682-9.

18. Hand PH, Vilasi V, Thor A, Ohuchi N, Schlom J. Quantitation of Harvey ras p21 enhanced expression in human breast and colon carcinomas. J Natl Cancer Inst. 1987;79(1):59-65.

19. Riou G, Barrois M, Sheng ZM, Duvillard P, Lhomme C. Somatic deletions and mutations of c-Ha-ras gene in human cervical cancers. Oncogene. 1988;3(3):329-33.

20. van Dijk MC, Bernsen MR, Ruiter DJ. Analysis of mutations in B-RAF, N-RAS, and H-RAS genes in the differential diagnosis of Spitz nevus and spitzoid melanoma. Am J Surg Pathol. 2005;29(9):1145-51.

21. Bender RP, McGinniss MJ, Esmay P, Velazquez EF, Reimann JD. Identification of HRAS mutations and absence of GNAQ or GNA11 mutations in deep penetrating nevi. Mod Pathol. 2013;26(10):1320-8.

22. Kiyohara T, Takata M, Itoh H, Kawami K, Yasuta M, Hayakawa K, et al. HRAS-mutated Spitz nevus on the cheek in a middle-aged man. Acta Derm Venereol. 2012;92(3):3267.

23. Raghavan SS, Peternel S, Mully TW, North JP, Pincus LB, LeBoit PE, et al. Spitz melanoma is a distinct subset of spitzoid melanoma. Mod Pathol. 2020;33(6):1122-34.

24. Li JY, Berger MF, Marghoob A, Bhanot UK, Toyohara JP, Pulitzer MP. Combined melanocytic and sweat gland neoplasm: cell subsets harbor an identical HRAS mutation in phacomatosis pigmentokeratotica. J Cutan Pathol. 2014;41(8):663-71.

25. Nemeth K, Szabo S, Cottrell CE, McNulty SM, Segura A, Sokumbi O, et al. Mosaic pathogenic HRAS variant in a patient with nevus spilus with agminated Spitz nevi and parametrial-uterine rhabdomyosarcoma. Br J Dermatol. 2018;178(3):804-6.

26. Pontoizeau J, Stefan A, Comoz F, Houlier A, Haddad V, Pissaloux D, et al. Agminated Spitz nevus arising in normal skin with redundant HRAS mutation. Eur J Dermatol. 2017;27(1):73-4.

27. Porubsky C, Teer JK, Zhang Y, Deschaine M, Sondak VK, Messina JL. Genomic analysis of a case of agminated Spitz nevi and congenital-pattern nevi arising in extensive nevus spilus. J Cutan Pathol. 2018;45(2):180-3.

28. Sarin KY, Sun BK, Bangs CD, Cherry A, Swetter SM, Kim J, et al. Activating HRAS mutation in agminated Spitz nevi arising in a nevus spilus. JAMA Dermatol. 2013;149(9):1077-81.

29. Da Forno PD, Pringle JH, Fletcher A, Bamford M, Su L, Potter L, et al. BRAF, NRAS and HRAS mutations in spitzoid tumours and their possible pathogenetic significance. Br J Dermatol. 2009;161(2):364-72.

30. Harvell JD, Bastian BC, LeBoit PE. Persistent (recurrent) Spitz nevi: a histopathologic, immunohistochemical, and molecular pathologic study of 22 cases. Am J Surg Pathol. 2002;26(5):654-61.

31. Sabater Marco V, Escutia Muñoz B, Morera Faet A, Mata Roig M, Botella Estrada R. Pseudogranulomatous Spitz nevus: a variant of Spitz nevus with heavy inflammatory infiltrate mimicking a granulomatous dermatitis. J Cutan Pathol. 2013;40(3):330-5.

32. Gerami P, Kim D, Compres EV, Zhang B, Khan AU, Sunshine JC, et al. Clinical, morphologic, and genomic findings in ROS1 fusion Spitz neoplasms. Mod Pathol. 2020.

33. Roh MR, Eliades P, Gupta S, Tsao H. Genetics of melanocytic nevi. Pigment Cell Melanoma Res. 2015;28(6):66172.

34. Iwahara T, Fujimoto J, Wen D, Cupples R, Bucay N, Arakawa T, et al. Molecular characterization of ALK, a receptor tyrosine kinase expressed specifically in the nervous system. Oncogene. 1997;14(4):439-49.

35. Hallberg B, Palmer RH. Mechanistic insight into ALK receptor tyrosine kinase in human cancer biology. Nat Rev Cancer. 2013;13(10):685-700.

36. Pulford K, Morris SW, Turturro F. Anaplastic lymphoma kinase proteins in growth control and cancer. J Cell Physiol. 2004;199(3):330-58.

37. Slupianek A, Nieborowska-Skorska M, Hoser G, Morrione A, Majewski M, Xue L, et al. Role of phosphatidylinositol 3-kinase-Akt pathway in nucleophosmin/anaplastic lymphoma kinase-mediated lymphomagenesis. Cancer Res. 2001;61(5):2194-9.

38. Zamo A, Chiarle R, Piva R, Howes J, Fan Y, Chilosi M, et al. Anaplastic lymphoma kinase (ALK) activates Stat3 and protects hematopoietic cells from cell death. Oncogene. 2002;21(7):1038-47.

39. Falini B, Bigerna B, Fizzotti M, Pulford K, Pileri SA, Delsol G, et al. ALK expression defines a distinct group of T/ null lymphomas ("ALK lymphomas") with a wide morphological spectrum. Am J Pathol. 1998;153(3):875-86.

40. Doyle LA, Mariño-Enriquez A, Fletcher CD, Hornick JL. ALK rearrangement and overexpression in epithelioid fibrous histiocytoma. Mod Pathol. 2015;28(7):904-12.

41. Niu HT, Zhou QM, Wang F, Shao Q, Guan YX, Wen XZ, et al. Identification of anaplastic lymphoma kinase break points and oncogenic mutation profiles in acral/mucosal melanomas. Pigment Cell Melanoma Res. 2013;26(5):64653.

42. Yeh I, Jorgenson E, Shen L, Xu M, North JP, Shain AH, et al. Targeted Genomic Profiling of Acral Melanoma. J Natl Cancer Inst. 2019;111(10):1068-77.

43. Amin SM, Haugh AM, Lee CY, Zhang B, Bubley JA, Merkel EA, et al. A Comparison of Morphologic and Mo- 
lecular Features of BRAF, ALK, and NTRK1 Fusion Spitzoid Neoplasms. Am J Surg Pathol. 2017;41(4):491-8.

44. Chung CT, Marrano P, Swanson D, Dickson BC, Thorner PS. Fusion of ALK to the melanophilin gene MLPH in pediatric Spitz nevi. Hum Pathol. 2019;87:57-64.

45. Kastnerova L, Martinek P, Grossmann P, Steiner P, Vanecek T, Kyclova J, et al. A Clinicopathological Study of 29 Spitzoid Melanocytic Lesions With ALK Fusions, Including Novel Fusion Variants, Accompanied by Fluorescence In Situ Hybridization Analysis for Chromosomal Copy Number Changes, and Both TERT Promoter and Next-Generation Sequencing Mutation Analysis. Am J Dermatopathol. 2020;42(8):578-92.

46. Kiuru M, Jungbluth A, Kutzner H, Wiesner T, Busam KJ. Spitz Tumors: Comparison of Histological Features in Relationship to Immunohistochemical Staining for ALK and NTRK1. Int J Surg Pathol. 2016;24(3):200-6.

47. Lee S, Barnhill RL, Dummer R, Dalton J, Wu J, Pappo A, et al. TERT Promoter Mutations Are Predictive of Aggressive Clinical Behavior in Patients with Spitzoid Melanocytic Neoplasms. Sci Rep. 2015;5:11200.

48. Raghavan SS, Kapler ES, Dinges MM, Bastian BC, Yeh I. Eruptive Spitz nevus, a striking example of benign metastasis. Sci Rep. 2020;10(1):16216.

49. Rand AJ, Flejter WL, Dowling CA, Brooke LM, Boland GM, Kroshinsky D, et al. Atypical ALK-positive Spitz tumors with 9p21 homozygous deletion: Report of two cases and review of the literature. J Cutan Pathol. 2018;45(2):136-40.

50. Yeh I, de la Fouchardiere A, Pissaloux D, Mully TW, Garrido MC, Vemula SS, et al. Clinical, histopathologic, and genomic features of Spitz tumors with ALK fusions. Am J Surg Pathol. 2015;39(5):581-91.

51. Busam KJ, Kutzner H, Cerroni L, Wiesner T. Clinical and pathologic findings of Spitz nevi and atypical Spitz tumors with ALK fusions. Am J Surg Pathol. 2014;38(7):925-33.

52. Melchers RC, Willemze R, van Doorn R, Jansen PM, Cleven AHG, Solleveld N, et al. Corresponding anaplastic lymphoma kinase-tropomyosin 3 (ALK-TPM3) fusion in a patient with a primary cutaneous anaplastic large-cell lymphoma and a Spitz nevus. JAAD Case Rep. 2019;5(11):970-2.

53. Newman S, Pappo A, Raimondi S, Zhang J, Barnhill R, Bahrami A. Pathologic Characteristics of Spitz Melanoma With MAP3K8 Fusion or Truncation in a Pediatric Cohort. Am J Surg Pathol. 2019;43(12):1631-7.

54. Saraggi D, Salmaso R, Zamuner C, Munari G, Lanza C, Alaibac MS, et al. Prevalence of ALK gene alterations among the spectrum of plexiform spitzoid lesions. J Am Acad Dermatol. 2018;79(4):728-35.

55. Fujimoto M, Togashi Y, Matsuzaki I, Baba S, Takeuchi $\mathrm{K}$, Inaba $\mathrm{Y}$, et al. A case report of atypical Spitz tumor harboring a novel MLPH-ALK gene fusion with discor- dant ALK immunohistochemistry results. Hum Pathol. 2018;80:99-103.

56. Perron E, Pissaloux D, Charon Barra C, Karanian M, Lamant L, Parfait S, et al. Melanocytic Myxoid Spindle Cell Tumor With ALK Rearrangement (MMySTAR): Report of 4 Cases of a Nevus Variant With Potential Diagnostic Challenge. Am J Surg Pathol. 2018;42(5):595-603.

57. Rousi EK, Koskivuo IO, Juteau SM, Talve LAI, Hernberg MM, Vihinen PP, et al. Different expression of BRAFV600E, ALK and PD-L1 in melanoma in children and adolescents: a nationwide retrospective study in Finland in 1990-2014. Acta Oncol. 2021;60(2):165-72. Epub 2020 Aug 20.

58. Brown RA, Wang JY, Raghavan SS, Zhang J, Wan DC, Born D, et al. ALK-positive compound Spitz nevus with extensive perineural and intraneural neurotropism. J Cutan Pathol. 2021;48(1):154-9. Epub 2020 Nov 8.

59. Ogawa K, Fukumoto T, Azukizawa H, Takeda M, Asada H. First Japanese case report of atypical Spitz tumor with an ALK rearrangement. J Dermatol. 2017;44(12):e342-3.

60. Busam KJ, Vilain RE, Lum T, Busam JA, Hollmann TJ, Saw RP, et al. Primary and Metastatic Cutaneous Melanomas Express ALK Through Alternative Transcriptional Initiation. Am J Surg Pathol. 2016;40(6):786-95.

61. Wiesner T, Lee W, Obenauf AC, Ran L, Murali R, Zhang $\mathrm{QF}$, et al. Alternative transcription initiation leads to expression of a novel ALK isoform in cancer. Nature. 2015;526(7573):453-7.

62. Farah M, Nagarajan P, Curry JL, Tang Z, Kim TB, Aung $\mathrm{PP}$, et al. Spitzoid melanoma with histopathological features of ALK gene rearrangement exhibiting ALK copy number gain: a novel mechanism of ALK activation in spitzoid neoplasia. Br J Dermatol. 2019;180(2):404-8.

63. Dunn ALJ, Gardner JM, Kaley JR, Bellamy W, Shalin SC. ALK Rearrangements Are Infrequent in Cellular Blue Nevus and Deep Penetrating Nevus. Am J Dermatopathol. 2018;40(7):469-78.

64. Drilon A, Jenkins C, Iyer S, Schoenfeld A, Keddy C, Davare MA. ROS1-dependent cancers - biology, diagnostics and therapeutics. Nat Rev Clin Oncol. 2020.

65. Donati M, Kastnerova L, Martinek P, Grossmann P, Sticová E, Hadravský L, et al. Spitz Tumors With ROS1 Fusions: A Clinicopathological Study of 6 Cases, Including FISH for Chromosomal Copy Number Alterations and Mutation Analysis Using Next-Generation Sequencing. Am J Dermatopathol. 2020;42(2):92-102.

66. Mitsui Y, Ogawa K, Takeda M, Nakanishi T, Azukizawa H, Asada H. First Japanese case of atypical Spitz tumor exhibiting ROS1 rearrangement. J Dermatol. 2018;45(9):e2489.

67. VandenBoom T, Quan VL, Zhang B, Garfield EM, Kong BY, Isales MC, et al. Genomic Fusions in Pigmented Spindle Cell Nevus of Reed. Am J Surg Pathol. 2018;42(8):1042-51. 
68. Rubin JB, Segal RA. Growth, survival and migration: the Trk to cancer. Cancer Treat Res. 2003;115:1-18.

69. Wang L, Busam KJ, Benayed R, Cimera R, Wang J, Denley $\mathrm{R}$, et al. Identification of NTRK3 Fusions in Childhood Melanocytic Neoplasms. J Mol Diagn. 2017;19(3):387-96.

70. de la Fouchardière A, Tee MK, Peternel S, Valdebran M, Pissaloux D, Tirode F, et al. Fusion partners of NTRK3 affect subcellular localization of the fusion kinase and cytomorphology of melanocytes. Mod Pathol. Epub 2020 Sep 23.

71. Lee CY, Sholl LM, Zhang B, Merkel EA, Amin SM, Guitart J, et al. Atypical Spitzoid Neoplasms in Childhood: A Molecular and Outcome Study. Am J Dermatopathol. 2017;39(3):181-6.

72. Yeh I, Busam KJ, McCalmont TH, LeBoit PE, Pissaloux D, Alberti L, et al. Filigree-like Rete Ridges, Lobulated Nests, Rosette-like Structures, and Exaggerated Maturation Characterize Spitz Tumors With NTRK1 Fusion. Am J Surg Pathol. 2019;43(6):737-46.

73. Yeh I, Tee MK, Botton T, Shain AH, Sparatta AJ, Gagnon A, et al. NTRK3 kinase fusions in Spitz tumours. J Pathol. 2016;240(3):282-90.

74. Zarabi SK, Azzato EM, Tu ZJ, Ni Y, Billings SD, Arbesman J, et al. Targeted next generation sequencing (NGS) to classify melanocytic neoplasms. J Cutan Pathol. 2020;47(8):691-704.

75. Friedman BJ, Hernandez S, Fidai C, Jiang A, Shwayder TA, Carskadon S, et al. A pediatric case of pigmented epithelioid melanocytoma with chromosomal copy number alterations in $15 \mathrm{q}$ and $17 \mathrm{q}$ and a novel NTRK3-SCAPER gene fusion. J Cutan Pathol. 2020;47(1):70-5.

76. Isales MC, Haugh AM, Bubley J, Verzì AE, Zhang B, Kudalkar E, et al. Genomic Assessment of Blitz Nevi Suggests Classification as a Subset of Blue Nevus Rather Than Spitz Nevus: Clinical, Histopathologic, and Molecular Analysis of 18 Cases. Am J Dermatopathol. 2018;40(2):118-24.

77. Cocco E, Scaltriti M, Drilon A. NTRK fusion-positive cancers and TRK inhibitor therapy. Nat Rev Clin Oncol. 2018;15(12):731-47.

78. Uguen A. Spitz Tumors With NTRK1 Fusions: TRK-A and pan-TRK Immunohistochemistry as Ancillary Diagnostic Tools. Am J Surg Pathol. 2019;43(10):1438-9.

79. Gatalica Z, Xiu J, Swensen J, Vranic S. Molecular characterization of cancers with NTRK gene fusions. Mod Pathol. 2019;32(1):147-53.

80. Hechtman JF, Benayed R, Hyman DM, Drilon A, Zehir A, Frosina D, et al. Pan-Trk Immunohistochemistry Is an Efficient and Reliable Screen for the Detection of NTRK Fusions. Am J Surg Pathol. 2017;41(11):1547-51.

81. Drilon A, Laetsch TW, Kummar S, DuBois SG, Lassen UN, Demetri GD, et al. Efficacy of Larotrectinib in TRK Fusion-Positive Cancers in Adults and Children. N Engl J Med. 2018;378(8):731-9.
82. Forschner A, Forchhammer S, Bonzheim I. NTRK gene fusions in melanoma: detection, prevalence and potential therapeutic implications. J Dtsch Dermatol Ges. 2020;18(12):1387-92.

83. Quan VL, Zhang B, Zhang Y, Mohan LS, Shi K, Wagner A, et al. Integrating Next-Generation Sequencing with Morphology Improves Prognostic and Biologic Classification of Spitz Neoplasms. J Invest Dermatol. 2020;140(8):1599608.

84. Rabes HM, Demidchik EP, Sidorow JD, Lengfelder E, Beimfohr C, Hoelzel D, et al. Pattern of radiation-induced RET and NTRK1 rearrangements in 191 post-chernobyl papillary thyroid carcinomas: biological, phenotypic, and clinical implications. Clin Cancer Res. 2000;6(3):1093103.

85. Lipson D, Capelletti M, Yelensky R, Otto G, Parker A, Jarosz $\mathrm{M}$, et al. Identification of new ALK and RET gene fusions from colorectal and lung cancer biopsies. Nat Med. 2012;18(3):382-4.

86. Yeh I, Botton T, Talevich E, Shain AH, Sparatta AJ, de la Fouchardiere A, et al. Activating MET kinase rearrangements in melanoma and Spitz tumours. Nat Commun. 2015;6:7174.

87. Hagemann D, Troppmair J, Rapp UR. Cot protooncoprotein activates the dual specificity kinases MEK-1 and SEK-1 and induces differentiation of PC12 cells. Oncogene. 1999;18(7):1391-400.

88. Salmeron A, Ahmad TB, Carlile GW, Pappin D, Narsimhan RP, Ley SC. Activation of MEK-1 and SEK-1 by Tpl2 proto-oncoprotein, a novel MAP kinase kinase kinase. Embo j. 1996;15(4):817-26.

89. Ceci JD, Patriotis CP, Tsatsanis C, Makris AM, Kovatch $\mathrm{R}$, Swing DA, et al. Tpl-2 is an oncogenic kinase that is activated by carboxy-terminal truncation. Genes Dev. 1997;11(6):688-700.

90. Gándara ML, López P, Hernando R, Castaño JG, Alemany $\mathrm{S}$. The $\mathrm{COOH}$-terminal domain of wild-type Cot regulates its stability and kinase specific activity. Mol Cell Biol. 2003;23(20):7377-90.

91. Quan VL, Zhang B, Mohan LS, Shi K, Isales MC, Panah E, et al. Activating Structural Alterations in MAPK Genes Are Distinct Genetic Drivers in a Unique Subgroup Of Spitzoid Neoplasms. Am J Surg Pathol. 2019;43(4):53848.

92. Houlier A, Pissaloux D, Masse I, Tirode F, Karanian M, Pincus LB, et al. Melanocytic tumors with MAP3K8 fusions: report of 33 cases with morphological-genetic correlations. Mod Pathol. 2020;33(5):846-57.

93. Quan VL, Panah E, Zhang B, Shi K, Mohan LS, Gerami $\mathrm{P}$. The role of gene fusions in melanocytic neoplasms. J Cutan Pathol. 2019;46(11):878-87.

94. Clark AM, Reynolds SH, Anderson M, Wiest JS. Mutational activation of the MAP3K8 protooncogene in lung cancer. Genes Chromosomes Cancer. 2004;41(2):99-108. 
95. Gruosso T, Garnier C, Abelanet S, Kieffer Y, Lemesre $\mathrm{V}$, Bellanger D, et al. MAP3K8/TPL-2/COT is a potential predictive marker for MEK inhibitor treatment in high-grade serous ovarian carcinomas. Nat Commun. 2015;6:8583.

96. Lee JH, Lee JH, Lee SH, Do SI, Cho SD, Forslund $\mathrm{O}$, et al. TPL2 Is an Oncogenic Driver in Keratocanthoma and Squamous Cell Carcinoma. Cancer Res. 2016;76(22):6712-22.

97. Sourvinos G, Tsatsanis C, Spandidos DA. Overexpression of the Tpl-2/Cot oncogene in human breast cancer. Oncogene. 1999;18(35):4968-73.

98. Kim D, Khan AU, Compres EV, Zhang B, Sunshine JC, Quan VL, et al. BRAF Fusion Spitz Neoplasms, Clinical, Morphologic and Genomic Findings in 6 Cases. J Cutan Pathol. 2020;47(12):1132-42.

99. Aramini JM, Vorobiev SM, Tuberty LM, Janjua H, Campbell ET, Seetharaman J, et al. The RAS-Binding Domain of Human BRAF Protein Serine/Threonine Kinase Ex- hibits Allosteric Conformational Changes upon Binding HRAS. Structure. 2015;23(8):1382-93.

100. Richtig G, Hoeller C, Kashofer K, Aigelsreiter A, Heinemann A, Kwong LN, et al. Beyond the BRAF(V)(600E) hotspot: biology and clinical implications of rare BRAF gene mutations in melanoma patients. Br J Dermatol. 2017;177(4):936-44.

101. Perron E, Pissaloux D, Neub A, Hohl D, Tartar MD, Mortier L, et al. Unclassified sclerosing malignant melanomas with AKAP9-BRAF gene fusion: a report of two cases and review of BRAF fusions in melanocytic tumors. Virchows Arch. 2018;472(3):469-76.

102. Kim D, Khan AU, Compres EV, Zhang B, Sunshine JC, Quan VL, et al. BRAF fusion Spitz neoplasms; clinical morphological, and genomic findings in six cases. J Cutan Pathol. 2020;47(12):1132-42.

103. Donati M, Kastnerova L, Ptakova N, Michal M, Kazakov DV. Polypoid Atypical Spitz Tumor With a Fibrosclerotic Stroma, CLIP2-BRAF Fusion, and Homozygous Loss of 9p21. Am J Dermatopathol. 2020;42(3):204-7. 